\title{
An inferior alveolar intraneural cyst: a case example and an anatomical explanation to support the articular theory within cranial nerves
}

\author{
Stepan Capek, MD, ${ }^{1,2}$ loannis G. Koutlas, DDS, MS, ${ }^{3}$ Rhys P. Strasia, DDS, ${ }^{4}$ \\ Kimberly K. Amrami, MD, ${ }^{5}$ and Robert J. Spinner, MD ${ }^{1}$

\begin{abstract}
Departments of ${ }^{1}$ Neurosurgery and ${ }^{5}$ Radiology, Mayo Clinic, Rochester; ${ }^{3}$ Division of Oral and Maxillofacial Pathology, School of Dentistry, University of Minnesota, Minneapolis, Minnesota; ${ }^{2}$ International Clinical Research Center, St. Anne's University Hospital Brno, Czech Republic; and ${ }^{4}$ Center for Oral \& Maxillofacial Surgery, Madison, Wisconsin
\end{abstract}

\begin{abstract}
The authors describe the case of an intraneural ganglion cyst involving a cranial nerve (V3), which was found to have a joint connection in support of an articular origin within the cranial nerves. An inferior alveolar intraneural cyst was incidentally discovered on a plain radiograph prior to edentulation. It was resected from within the mandibular canal with no joint connection perceived at surgery. Histologically, the cyst was confirmed to be an intraneural ganglion cyst. Reinterpretation of the preoperative CT scan showed the cyst arising from the temporomandibular joint. This case is consistent with the articular (synovial) theory of intraneural ganglion cysts. An anatomical explanation and potential joint connection are provided for this case as well as several other cases of intraneural cysts in the literature, and thus unifying cranial nerve involvement with accepted concepts of intraneural ganglion cyst formation and propagation.
\end{abstract}

http://thejns.org/doi/abs/10.3171/2014.12.JNS14798

KEY WORDS intraneural ganglion; intraneural cyst; cranial nerve; trigeminal; hypoglossal; facial; peripheral nerve

I NTRANEURAL ganglia are rare, nonneoplastic mucinous cysts contained within nerves. They are becoming understood because of their joint-related origin and a unifying articular (synovial) theory. ${ }^{30}$ The most common site is the peroneal nerve where the intraneural ganglion arises from the anterior portion of the superior tibiofibular joint. These cysts have been described within a large number of peripheral nerves and have derived from neighboring synovial joints. We describe the case of a cranial nerve cyst and provide an anatomical explanation for our and other reported cases of ganglion cysts within cranial nerves.

\section{Case Report}

History and Examination

A 46-year-old woman presented to an oral surgeon for edentulation. Prior to surgery her general dentist obtained a radiograph, which showed a radiolucent cystic dilation near the right angle of the right mandible. The patient did not describe any pain, numbness, or other symptoms attributable to the lesion. Subsequent CT scanning of the facial bones with sagittal and coronal reformatting was performed (Fig. 1) and showed an intraosseous cyst within the mandibular canal near the mandibular angle. The cyst was not connected to any dental structures. The cortical layers of the adjacent bone were markedly thinned, but there was no destruction or breakthrough.

\section{Treatment}

Five months later the patient underwent excisional biopsy at a local hospital. The cyst was approached intraorally using a sagittal split osteotomy. An approximately 2-cm cyst was dissected free from within the inferior alveolar nerve. No joint connection was noted. The inferior alveolar nerve remained intact.

ABBREVIATIONS MIP = maximum intensity projection; TMJ = temporomandibular joint.

SUBMITTED April 9, 2014. ACCEPTED December 10, 2014.

INCLUDE WHEN CITING Published online February 6, 2015; DOI: 10.3171/2014.12.JNS14798.

DISCLOSURE The authors report no conflict of interest concerning the materials or methods used in this study or the findings specified in this paper. Dr. Capek is supported by the European Regional Development Fund, Project FNUSA-ICRC (No. CZ.1.05/1.1.00/02.0123). 

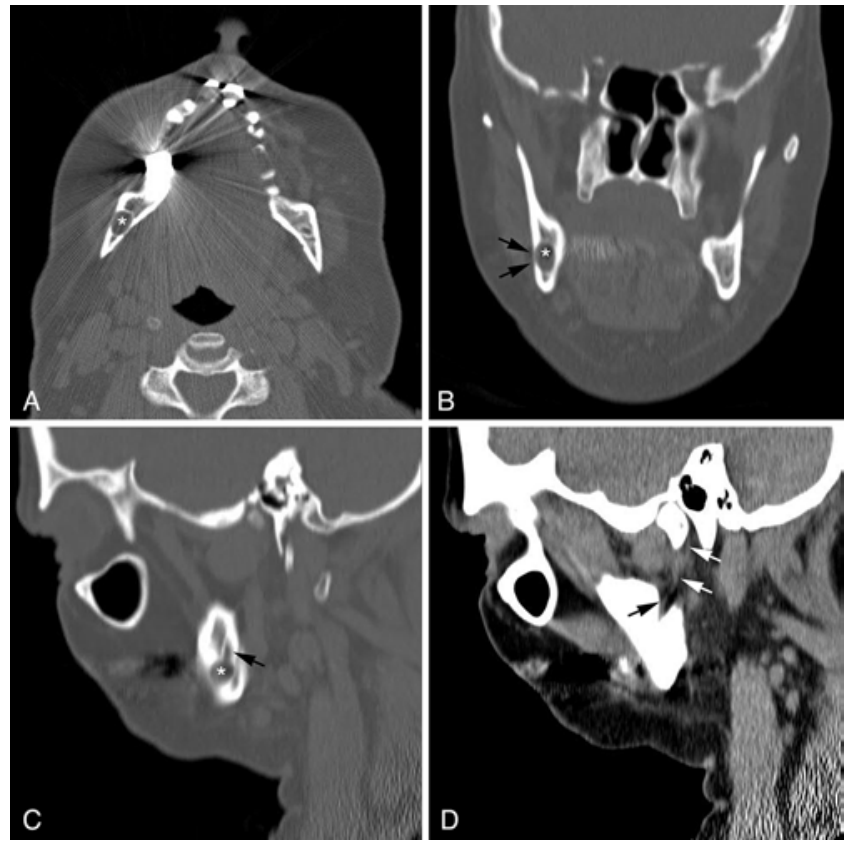

FIG. 1. Preoperative CT scans. A: Axial nonenhanced CT scan of the facial bones showing a benign intraosseous cyst within the right mandible (asterisk). B: Coronal reformatted image (from same data set as in panel A) showing the intraosseous cyst (asterisk) with benign anterior and lateral erosion of the cortex (arrows). C: Sagittal reformatted image showing the cyst (asterisk) extending into an expanded mandibular foramen (arrow). D: Oblique sagittal maximum intensity projection (MIP) from the CT data set demonstrating proximal extension of the cyst from the mandible posteriorly and medially through the expanded foramen (black arrow) to the capsule of the TMJ (white arrows). The soft tissue windowing displays the cyst as an intermediate-density structure.

\section{Posttreatment Findings}

Histological preparations were sent to the University of Minnesota Division of Oral Pathology for consult and to confirm the diagnosis. Subsequently, the case was reviewed at the Mayo Clinic (Fig. 2), and the diagnosis of intraneural ganglion cyst was favored.

Aware of the articular theory, we hypothesized that the cyst arose from a neighboring joint and propagated through the articular branch from the auriculotemporal nerve to the parent inferior alveolar nerve. The preoperative CT scan was re-reviewed. The available image data were manipulated using standard workstation tools (Volume Viewer, Advantage Windows 4.2, GE Healthcare) to create oblique maximum intensity projection (MIP) images with both bone and soft tissue windowing. A previously unrecognized connection to the temporomandibular joint (TMJ) was apparent (Fig. 1). Attempts to obtain postoperative MRI to look for persistent or recurrent cyst were unsuccessful given the patient's claustrophobia.

\section{Discussion}

This case is unique in that it describes an intraneural ganglion cyst affecting a cranial nerve that was found to have a joint connection, in this case to the TMJ.

Synovial, or ganglion, cysts derived from synovial joints are well known. (Note that the terms "ganglia"

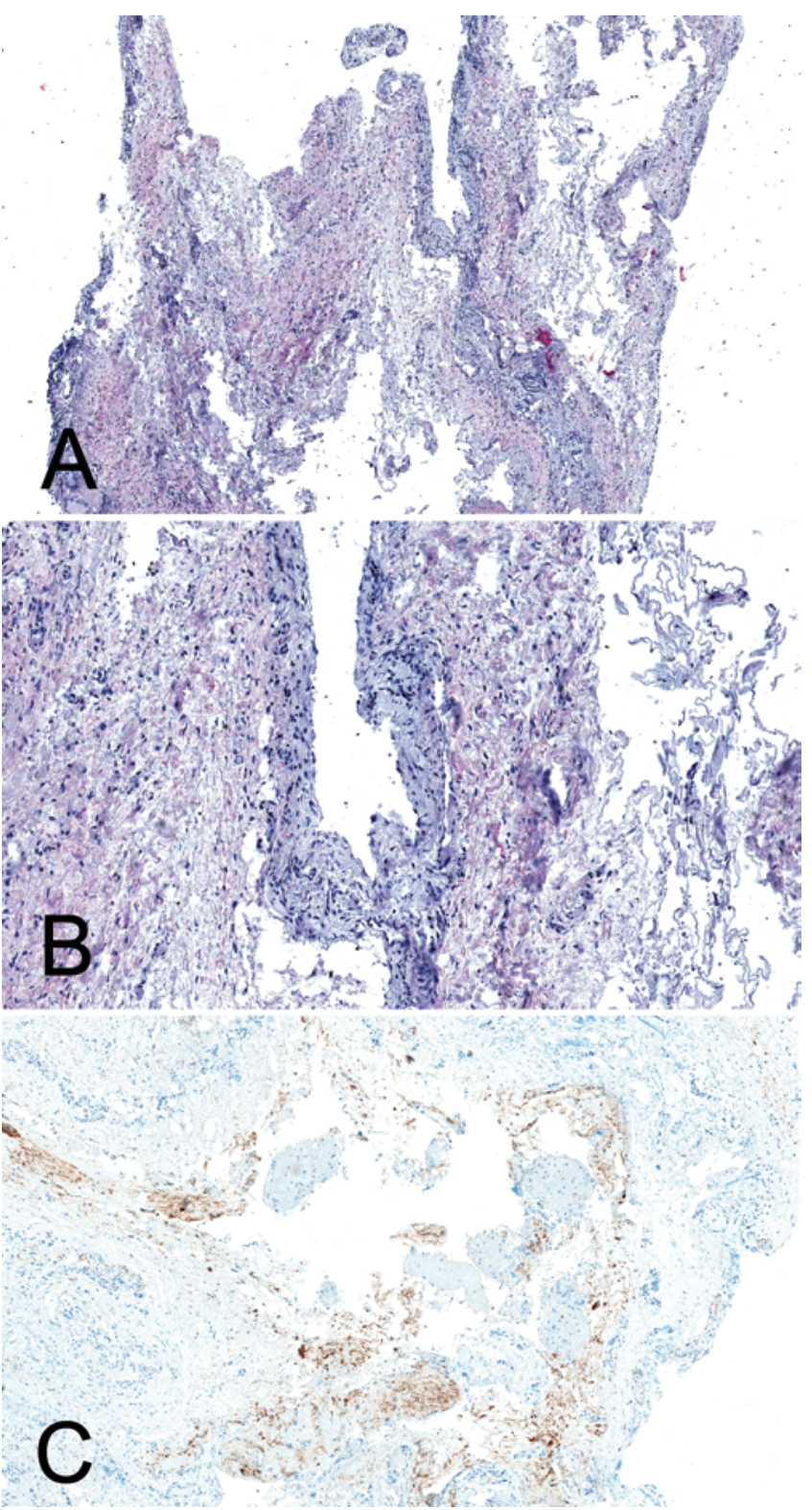

FIG. 2. Histology. A: Cystic lesion surrounded by loose connective tissue. $H \& E$, original magnification $\times 40$. B: A higher magnification features another area of the lumen and surrounding wall. $H \& E$, original magnification $\times 100$. C: The cyst lining was composed of perineurial cells highlighted by epithelial membrane antigen (EMA). EMA-avidin biotin complex with hematoxylin counterstain, original magnification $\times 20$.

and "synovial cysts" are used interchangeably in the literature.) The TMJ is a synovial joint with more than 50 cases of (extraneural) cysts reported in the literature. Extraneural cysts in this location can be asymptomatic or symptomatic (causing neural symptoms due to extrinsic nerve compression $3,4,8,23,33$ or mastication difficulties because of the mass ${ }^{2,7,20,32}$ ). They are derived from the TMJ via non-neural pedicles and can extend in different directions, even intraosseously ${ }^{2,8,16,26}$ or intracranially ${ }^{18,23,33}$ (Fig. 3B). As a synovial joint, it is logical that this joint can also form an intraneural ganglion. According to the articular (synovial) theory, intraneural cysts are formed when joint 


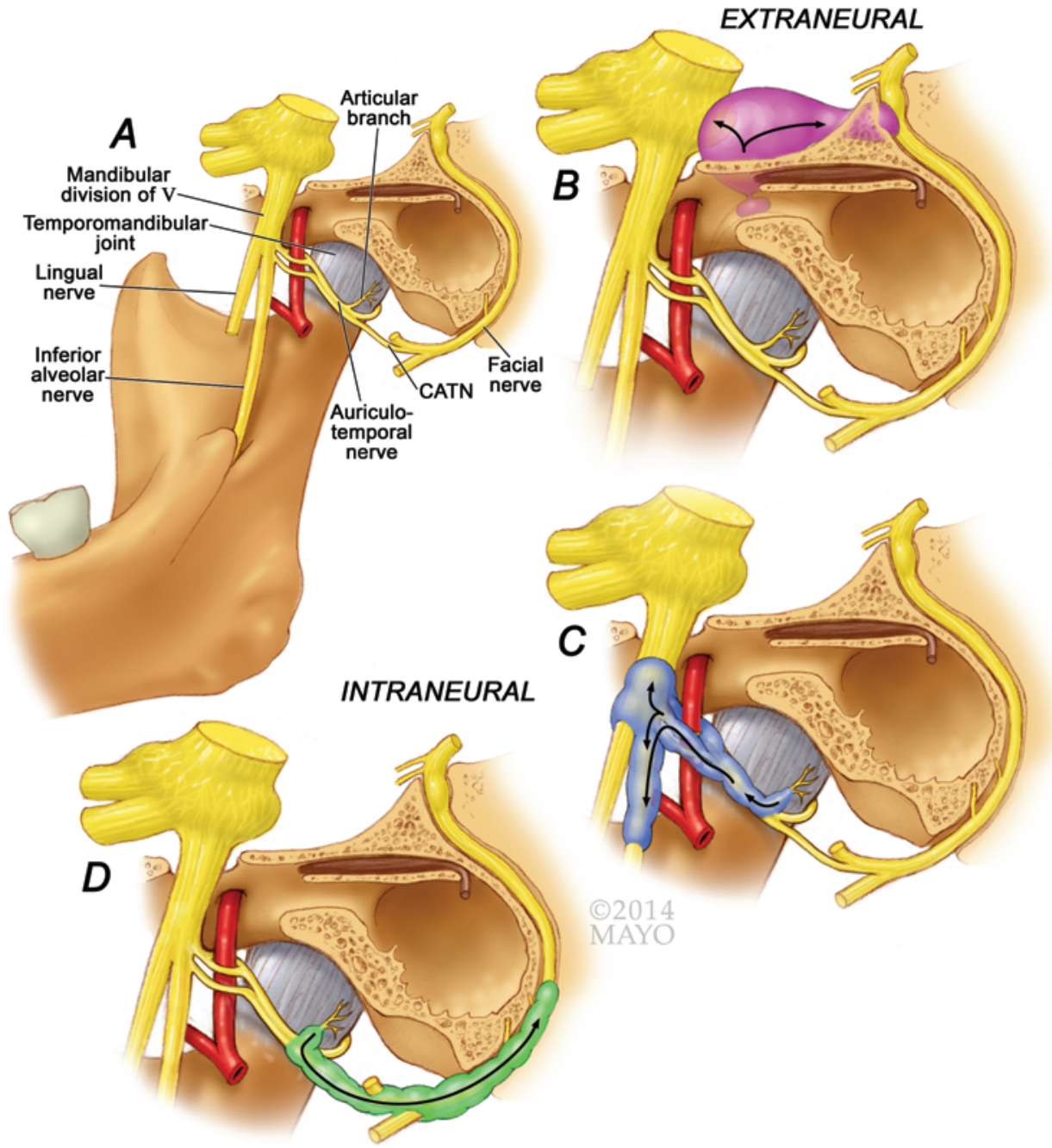

FIG. 3. Artist's rendering of anatomy and pathological correlation of the TMJ region and ganglion cysts arising from it. A: IIlustration showing normal anatomy of the medial aspect of the TMJ. Note the articular branch of the auriculotemporal nerve and the highly variable $9,17,24$ communicating auriculotemporal nerve (CATN). B: Example of an extraneural ganglion cyst arising from the TMJ. The cyst erodes the bone and compresses the trigeminal and facial nerves. C: Example of an intraneural ganglion cyst involving the articular branch and the inferior alveolar nerve. D: Example of an intraneural ganglion cyst dissecting along the articular branch into the facial nerve via the communicating auriculotemporal nerve. Copyright Mayo Foundation for Medical Education and Research. Published with permission.

fluid propagates from the neighboring synovial joint along the articular branch into the main parent nerve. The TMJ is innervated by the mandibular portion of the trigeminal nerve (V3), namely an articular branch of the auriculotemporal nerve. Accessory innervation is provided by a branch from the masseteric nerve or a branch penetrating the lateral pterygoid muscle (the latter, therefore, most probably arising from the lateral pterygoid nerve; Fig. $3 \mathrm{~A}){ }^{10}$ In our case, we believe that the auriculotemporal nerve acted as a conduit for propagation of the cyst to the inferior alveolar nerve (Fig. 3C).

Our review of the literature revealed several reports that did not propose a mechanism of cyst formation but could also be explained by the articular theory. The only other example of an intraneural cyst affecting the trigeminal nerve also involved the inferior alveolar nerve and had similar clinicopathological findings. ${ }^{1}$ Cases of intraneural cysts of the facial nerve have also been reported. ${ }^{21,27} \mathrm{We}$ wonder if these cases are examples of intraneural ganglion cysts, which can be anatomically explained by articular branches from the TMJ via the communicating auriculotemporal nerve ${ }^{6,17,24}$ to the parent facial nerve (Fig. 3D).

A separate group are so-called hypoglossal cysts, ganglia producing hypoglossal nerve compression. There are 3 reported intraneural cases. ${ }^{5,12,25}$ Seven extraneural cases have been documented, ${ }^{11,13-15,19,22,28} 5$ derived from the atlantooccipital joint ${ }^{11,13,14,22,28}$ and 2 from the atlantoaxial joint. ${ }^{15,19}$ There is some controversy about whether the 3 mentioned "intraneural" cases are in fact intra- or extraneural and whether joint connections existed in these cases. We believe ${ }^{29,31}$ that all of the reported examples are extraneural and have joint connections. We have also introduced a possible anatomical explanation that could explain the occurrence of an intraneural ganglion. ${ }^{31}$

We report this case and our reexamination of the available imaging as a proof of concept; however, we acknowl- 
edge the limitations of our report. The only available imaging in the patient was a CT scan of the facial bones, which was acquired with 2-mm axial slices without contrast. Images were not overlapping so that the coronal and sagittal reformatted images are somewhat limited by artifact as well as by the fact that images rather than raw data were used to create the reformatted images. We were able to manipulate the available image data through the use of a volumetric viewer to create MIP images at a variety of obliquities (including the image presented in Fig. 3D). Usable 3D reconstructions could not be performed because of the relatively low resolution and non-isotropic data set available to us. Ideally, dedicated MRI and CT scanning of the right TMJ would have been obtained with high spatial resolution and volumetric acquisitions, which would have allowed seamless 2D and 3D reconstructions and a high degree of detail. Contrast enhancement would have been useful to better delineate the intraneural cyst from adjacent muscle. Were it available in the patient, CT or MRI TMJ arthrography would have conclusively shown the cyst origin from that joint. Surgery was performed without exploration of the TMJ and without confirmation of a joint connection via the articular branch of the auriculotemporal nerve.

\section{Conclusions}

We described a mechanism by which a cranial nerve example of an intraneural ganglion cyst could be explained. We believe that this cyst arose from the TMJ, dissected within the articular branch (auriculotemporal nerve), and propagated within the inferior alveolar nerve, which would be supported by the articular theory for intraneural ganglia. We further suggest that our anatomical theory would similarly explain other rare examples of intraneural cysts within the trigeminal or facial nerve.

\section{Acknowledgment}

We appreciate the assistance of Bernd W. Scheithauer, who had reviewed this case in detail prior to his premature death.

\section{References}

1. Akamine RN: Cystic degeneration of the mandibular nerve: report of case. J Oral Surg 27:420-426, 1969

2. Albright JT, Diecidue RJ, Johar A, Keane WM: Intraosseous ganglion of the temporomandibular joint presenting with otorrhea. Arch Otolaryngol Head Neck Surg 126:665-668, 2000

3. Ali ZA, Busaidy KF, Wilson J: Unusual presentation of a ganglion cyst of the temporomandibular joint: case report and distinction from synovial cyst. J Oral Maxillofac Surg 64:1300-1302, 2006

4. Ansari H, Robertson CE, Lane JI, Viozzi CF, Garza I: Auriculotemporal neuralgia secondary to TMJ synovial cyst: a rare presentation of a rare entity. Headache 53:1662-1665, 2013

5. Baldauf J, Junghans D, Schroeder HWS: Endoscope-assisted microsurgical resection of an intraneural ganglion cyst of the hypoglossal nerve. J Neurosurg 103:920-922, 2005

6. Baumel JJ, Vanderheiden JP, McElenney JE: The auriculotemporal nerve of man. Am J Anat 130:431-440, 1971

7. Bonacci CE, Lambert BJ, Pulse CL, Israel HA: Inflamma- tory synovial cyst of the temporomandibular joint: a case report and review of the literature. J Oral Maxillofac Surg 54:769-773, 1996

8. Bridgeman AM, Wiesenfeld D, Buchanan M: Intraosseous ganglion of the mandibular condyle: a case report. J Oral Maxillofac Surg 56:1449-1451, 1998

9. Čihák R, Grim M, Druga R: Anatomie 3. Praha: Grada, 2004

10. Davidson JA, Metzinger SE, Tufaro AP, Dellon AL: Clinical implications of the innervation of the temporomandibular joint. J Craniofac Surg 14:235-239, 2003

11. Elhammady MS, Farhat H, Aziz-Sultan MA, Morcos JJ: Isolated unilateral hypoglossal nerve palsy secondary to an atlantooccipital joint juxtafacet synovial cyst. J Neurosurg Spine 10:234-239, 2009

12. Gambhir S, Mujic A, Hunn A: An intraneural ganglion cyst causing unilateral hypoglossal nerve palsy. J Clin Neurosci 18:1114-1115, 2011

13. Giordano M, Gerganov VM, Samii A, Samii M: Intradural extraneural bilobate ganglion cyst of the atlanto-occipital joint compressing the hypoglossal nerve. J Clin Neurosci 19:472-473, 2012

14. Hénaux PL, Hamlat A, Riffaud L, Guégan Y, Morandi X: Spontaneous regression of a symptomatic atlanto-occipital joint cyst. Case report. Neurochirurgie 57:129-132, 2011

15. Hewett RM, Stewart GE: Neurological picture. Isolated hypoglossal nerve palsy caused by synovial cyst. J Neurol Neurosurg Psychiatry 82:376-377, 2011

16. Khachi S, Gubbels SP, Robinson RA, Hansen MR: Ganglion cyst presenting as an external auditory canal mass. Otolaryngol Head Neck Surg 144:131-132, 2011

17. Kwak HH, Park HD, Youn KH, Hu KS, Koh KS, Han SH, et al: Branching patterns of the facial nerve and its communication with the auriculotemporal nerve. Surg Radiol Anat 26:494-500, 2004

18. Lee CK, Oh MH, Park KH: Ganglion cyst in the external auditory canal. Ear Nose Throat J 92:E33, 2013

19. Mendes-Araújo L, Rangel C, Domingues RC, Gasparetto EL: Case report. Atlantoaxial synovial cyst causing isolated unilateral hypoglossal nerve paralysis. Br J Radiol 83:e35-e38, 2010

20. Meng JH, Guo CB, Ma XC: [Diagnosis and treatment of the ganglion cysts and synovial cysts arising from the temporomandibular joints.] Beijing Da Xue Xue Bao 46:43-47, 2014 (Chinese)

21. Michalopoulos K, Bajaj Y, Strachan DR: Recurrent facial nerve palsy caused by a facial cyst. Br J Hosp Med (Lond) 69: 475,2008

22. Mujic A, Hunn A, Liddell J, Taylor B, Havlat M, Beasley T: Isolated unilateral hypoglossal nerve paralysis caused by an atlanto-occipital joint synovial cyst. J Clin Neurosci 10:492-495, 2003

23. Mumert ML, Altay T, Shelton C, Harnsberger HR, Couldwell WT: Ganglion cyst of the temporomandibular joint with intracranial extension in a patient presenting with seventh cranial nerve palsy. J Neurosurg 116:310-312, 2012

24. Namking M, Boonruangsri P, Woraputtaporn W, Güldner FH: Communication between the facial and auriculotemporal nerves. J Anat 185:421-426, 1994

25. Nonaka Y, Grossi PM, Filomena CA, Friedman AH, Fukushima T: Unilateral hypoglossal nerve palsy caused by an intraneural ganglion cyst. J Neurosurg 113:380-383, 2010

26. Patel NS, Pellettiere EV, Southwick HW: Intraosseous ganglion of the temporomandibular joint. J Oral Surg 37:829831, 1979

27. Pertzborn SL, Reith JD, Mancuso AA, Antonelli PJ: Epineurial pseudocysts of the intratemporal facial nerve. Otol Neurotol 24:490-493, 2003

28. Santín-Amo JM, Castro-Bouzas D, Prieto-González A, 
Arias-Gómez M, Arcos-Algaba A, Díaz-Cabanas L, et al: [Isolated hypoglossal nerve palsy secondary to an atlantoccipital joint synovial cyst. Case report and literature review.] Neurocirugia (Astur) 21:322-325, 2010 (Span)

29. Spinner RJ, Atkinson JLD, Maus TP: Intraneural ganglion. J Neurosurg 113:1331-1333, 2010 (Letter)

30. Spinner RJ, Atkinson JLD, Tiel RL: Peroneal intraneural ganglia: the importance of the articular branch. A unifying theory. J Neurosurg 99:330-343, 2003

31. Spinner RJ, Carmichael SW, Atkinson JLD: Intraneural ganglion cyst. J Neurosurg 104:990-992, 2006 (Letter)

32. Suhr MAA, Mager A: Unilateral non-occlusion secondary to a ganglionic cyst of the temporomandibular joint (TMJ). J Craniomaxillofac Surg 41:e5-e7, 2013

33. Vender JR, Hughes BD, Figueroa R, Jensen MA: Temporomandibular joint cyst presenting as trigeminal neuropathy and middle fossa mass: case report. Neurosurgery 59:E938, 2006

\section{Author Contributions}

Conception and design: Spinner, Capek. Acquisition of data: all authors. Analysis and interpretation of data: Spinner, Capek, Koutlas, Amrami. Drafting the article: Spinner, Capek, Koutlas, Amrami. Critically revising the article: Spinner, Capek, Amrami. Reviewed submitted version of manuscript: all authors. Approved the final version of the manuscript on behalf of all authors: Spinner. Study supervision: Spinner.

\section{Correspondence}

Robert J. Spinner, Mayo Clinic, 200 1st St. SW, Gonda 8-214, Rochester, MN 55905. email: spinner.robert@mayo.edu. 